\title{
COMPORTAMENTO DE CIDADANIA ORGANIZACIONAL: AS VISÕES DE COLABORADORES E DE GESTORES DE UMA INDÚSTRIA DE ELETRODOMÉSTICOS ${ }^{1}$
}

\author{
Vívian Flores Costa ${ }^{2}$ \\ Vania de Fátima Barros Estivalete ${ }^{3}$ \\ Taís de Andrade ${ }^{4}$
}

http://dx.doi.org/10.1590/1413-2311.166.62241

\begin{abstract}
RESUMO
Este estudo tem o objetivo central identificar os comportamentos de cidadania organizacional (CCO) predominantes no contexto organizacional, a partir da visão de colaboradores e de gestores de uma indústria de eletrodomésticos. Para tanto, realizou-se uma pesquisa descritiva, de natureza quantitativa e qualitativa, concretizada por meio de um estudo de caso em uma empresa fabricante de eletrodomésticos. Inicialmente, na etapa quantitativa, participaram 302 colaboradores pertencentes a diversas posições hierárquicas da empresa pesquisada, os quais responderam um questionário elaborado a partir do modelo Escala de Civismo nas Organizações (ECO) de Porto e Tamayo (2003). Em um segundo momento, na etapa qualitativa, participaram 10 gestores da empresa investigada, com os quais se efetivaram entrevistas semiestruturadas, sendo o protocolo elaborado à luz do modelo de Porto e Tamayo (2003). Os principais resultados encontrados expõem que, no que tange aos $\mathrm{CCO}$, os comportamentos de Proteção ao sistema e de Cooperação com os colegas foram os indicados pelos colaboradores e gestores como os mais presentes no contexto organizacional investigado. Em contrapartida, na visão dos colaboradores, o autotreinamento e o comportamento de sugestão à gestão organizacional são os menos praticados no ambiente de trabalho. Contudo, a visão dos gestores apresentou algumas dissensões, visto que apontaram esses comportamentos como recorrentes nos membros da organização.
\end{abstract}

Palavras-Chave: Comportamento de Cidadania Organizacional. Colaboradores. Gestores.

\section{ORGANIZATIONAL CITIZENSHIP BEHAVIOR: THE VIEWS OF EMPLOYEES AND MANAGERS OF A HOME APPLIANCES INDUSTRY}

\author{
ABSTRACT \\ ${ }^{1}$ Recebido em 16/02/2016; aprovado em 20/06/2017. \\ ${ }^{2}$ Universidade Federal de Santa Maria - vivianfc13@gmail.com. \\ ${ }^{3}$ Universidade Federal de Santa Maria - vaniaestivalete@ufsm.br. \\ ${ }^{4}$ Universidade Federal de Santa Maria - tais0206@gmail.com. \\ REAd | Porto Alegre - Vol. 23 - No Especial - Dezembro 2017 - p. 262-291
}


This study's main objective is to identify the organizational citizenship behaviors (OCB) prevalent in the organizational context from the perspective of employees and managers of a home appliances industry. To this end, we carried out a descriptive study of quantitative and qualitative nature, accomplished through a case study in an appliance manufacturing company. Initially, in the quantitative stage, 302 employees belonging to different hierarchical positions the Company searched answered a questionnaire drawn from the Scale of Civility in Organizations from Port and Tamayo (2003). In a second step, the qualitative one, 10 managers of the investigated company participated in semi-structured interviews, and the protocol was drawn up in the light of the Porto and Tamayo (2003) model. The main findings are that, with respect to the $\mathrm{OCB}$, the behaviors of the protection system and cooperation with colleagues were nominated by employees and managers as the most present in the organizational context investigated. In contrast, in the view of the employees, selftraining and organizational management suggestions are less practiced in the workplace. However, the vision of managers presented some disagreements, as pointed out these behaviors as recurrent in the members of the organization.

Keywords: Organizational Citizenship Behaviors. Employees. Managers.

\section{CONDUCTA DE CIUDADANÍA ORGANIZACIONAL: LA VISIÓN DE EMPLEADOS Y DIRECTIVOS DE UNA INDUSTRIA DE ELECTRODOMÉSTICOS}

\section{RESUMEN}

Este estudio pretende identificar las predominantes conductas de ciudadanía organizacional (CCO) en el contexto de una organización, desde la perspectiva de los empleados y directivos de una industria de electrodomésticos. Para eso, se realizó un estudio descriptivo de naturaleza cuantitativa y cualitativa, llevado a cabo a través de un estudio de caso. Inicialmente, em la fase cuantitativa, 302 empleados pertenecientes a diferentes posiciones jerárquicas de la empresa respondieron a un cuestionario desarrollado a partir del modelo Escala de Civismo en las Organizaciones (ECO) de Porto y Tamayo (2003). En un segundo momento, el cualitativo, participaron 10 directivos de la empresa investigada, con los que se realizaron entrevistas semi-estructuradas, siendo el protocolo elaborado teniendo em cuenta el modelo de Porto y Tamayo (2003). Los principales resultados indican que, con respecto a las $\mathrm{CCO}$, los comportamientos de protección del sistema y cooperación con sus compañeros fueron los nominados por empleados y directivos como los más presentes en el contexto organizacional investigado. Por otra parte, a juicio de los empleados, la autoformación y el comportamiento de sugerencia a la gestión organizacional son menos practicadas en el lugar de trabajo. Sin embargo, la visión de los directivos presenta algunas disensiones, como ha señalado estos comportamientos como demandantes en los miembros de la organización.

Palabras-Clave: Conducta de Ciudadanía Organizacional. Empleados. Directivos.

\section{INTRODUÇÃO}

Nas últimas décadas, constatou-se um aumento nos estudos sobre comportamento de REAd | Porto Alegre - Vol. 23 - No Especial - Dezembro 2017 - p. 262-291 
cidadania organizacional (CCO) (PODSAKOFF et al., 2014). Este interesse em relação ao tema não é surpreendente, uma vez que as pesquisas demonstram que os atos de cidadania nas organizações aumentam a produtividade, auxiliam as organizações a competir com recursos limitados, e favorecem uma maior cooperação entre os trabalhadores, colaborando, inclusive, com a satisfação dos clientes (PODSAKOFF; MACKENZIE, 1994).

As investigações sobre tal comportamento mostram que a vontade dos trabalhadores em cumprir o seu papel formal não é suficiente para assegurar à eficácia organizacional. Pelo contrário, é o aspecto voluntário, ligados a atos espontâneos, inovadores e cooperativos dos trabalhadores, que prevê melhores indicadores de eficácia diante das diversas situações organizacionais (NASRA; HEILBRUNN, 2015).

Neste sentido, Yaghoubi, Yazdani e Khornegah (2011) explicam que as condutas de cidadania fazem com que os indivíduos assumam consciência e desenvolvam um comportamento pró-ativo nas organizações. Segundo os autores, estes comportamentos denotam, também, uma preocupação com os demais indivíduos, por meio da manifestação de atitudes de participação e auxílio na solução de problemas.

Todavia, mesmo reconhecida à relevância do $\mathrm{CCO}$, percebe-se que existem aspectos pertinentes ao tema insuficientemente explorados, como o estudo de suas múltiplas dimensões em diferentes contextos (MARINOVA; MOON; VAN DYNE, 2010). Especificamente no Brasil, a apreciação da produção científica sobre o tema, nos principais eventos e periódicos da área de Administração, demonstra que a temática ainda é pouco empreendida em âmbito nacional (ESTIVALETE; COSTA; ANDRADE, 2014).

Assim, pondera-se pertinente contribuir com a pesquisa acerca do $\mathrm{CCO}$, concretizando o presente estudo que visa identificar os comportamentos de cidadania organizacional predominantes no contexto organizacional, a partir da visão de colaboradores e de gestores de uma indústria de eletrodomésticos. Para a consecução desse objetivo, realizou-se uma pesquisa descritiva, de natureza quantitativa e qualitativa, desenvolvida por meio de um estudo de caso em uma empresa fabricante de eletrodomésticos, pertencente à região do Vale do Rio Pardo, no Rio Grande do Sul (RS).

Ressalta-se que a temática parece assumir ampla relevância no cenário da organização selecionada como o caso de estudo desta pesquisa, visto que, apesar da evolução dos equipamentos e dos métodos facilitarem os objetivos de produção nas indústrias, são os trabalhadores que frequentemente absorvem o impacto da necessidade de variações no processo produtivo (VINK; STAHRE, 2006). Desta forma, como esclarece Martin (1997, p.

REAd | Porto Alegre - Vol. 23 - No Especial - Dezembro 2017 - p. 262-291 
10), para alavancar os processos neste setor o trabalhador deve ter uma "maior responsabilidade por tomadas de decisões imediatas e uma participação mais ativa", sendo essencial que se sinta envolvido na organização e anseie contribuir com comportamentos além dos prescritos pelo sistema formal (YAGHOUBI; SALARZEHI; MOLOUDI, 2013).

Deste modo, diante da importância do CCO, progredir nas pesquisas sobre a temática a partir de perspectivas quantitativas e qualitativas, especificamente no setor industrial, torna este estudo relevante e inovador. A análise dos Comportamentos de Cidadania Organizacional praticados pelos colaboradores da organização investigada irá possibilitar um aprofundamento acerca da natureza individual e relacional, na qual está alicerçado o construto foco desse estudo, contribuindo para o avanço das pesquisas sobre o tema.

\section{COMPORTAMENTO DE CIDADANIA ORGANIZACIONAL}

O termo cidadania tem sido historicamente empregado para elucidar, pelo conteúdo social, cultural, político e econômico, a condição do ser humano como detentor de direitos e deveres, enquanto membro de uma sociedade (MILLER, 2002). Atualmente, no entanto, o conceito de cidadania admite uma amplitude ainda maior de significados, passando a ser usado também a subsidiar teoricamente a concepção sobre determinados comportamentos que são emitidos em ambientes específicos, tais como o organizacional (GOMES et al., 2014).

A teoria sobre comportamentos de cidadania no âmbito das organizações fundamentase em conceitos difundidos por Barnard (1938) e Katz e Kahn (1974). Barnard (1938) afirmava que as organizações são sistemas de atividades em que duas ou mais pessoas integram esforços de forma consciente e coordenada, agregando-se em função de três fatores: capacidade de comungar um propósito, boa vontade em relação aos processos organizacionais, e capacidade de comunicar-se (CRUZ JÚNIOR, 2004). Baseados nesses conceitos, Katz e Kahn (1974) identificaram três tipos básicos de comportamentos fundamentais para o funcionamento organizacional: ingressar e permanecer no sistema, comportamento fidedigno e comportamento inovador e espontâneo.

Essas teorias constituíram os pilares para a noção de Comportamento de Cidadania Organizacional, explorada inicialmente nos estudos de Organ e seus colaboradores (ORGAN, 1977, 1988; BATEMAN; ORGAN, 1983; SMITH; ORGAN; NEAR, 1983). Inclusive, diante dos diferentes postulados encontrados para o CCO, Podsakoff et al. (2014) destacam que a definição mais amplamente aceitável para o conceito de CCO compreende sua associação a

REAd | Porto Alegre - Vol. 23 - No Especial - Dezembro 2017 - p. 262-291 
um conjunto de contribuições informais, individuais e discricionários, que os participantes de uma organização podem manifestar ou inibir, sem ter que responder a sanções ou objetivos formais, pertencente à Organ (1988).

Contudo, algumas pesquisas mais recentes (VAN DYNE; ANG; KOH, 2008; PODSAKOFF et al., 2009; MARINOVA; MOON; VAN DYNE, 2010) sinalizam para os benefícios potenciais de uma abordagem mais sutil quanto a sua conceituação. Uma abordagem que considere, primeiramente, que os colaboradores diferem na medida em que percebem os CCO como parte do exercício de seu papel ou extra papel nas organizações, e que esses atos podem ser percebidos como recompensados pelas organizações, por meio de avaliações de desempenho, promoções ou reconhecimento.

No que tange às suas dimensões, apesar de não haver um consenso, prevelace nos estudos sobre o tema a consideração do CCO como um construto multidimensional (PODSAKOFF et al., 2000; PODSAKOFF et al., 2014). Em relação às pesquisas em âmbito nacional, Siqueira (1995) concebeu uma medida multidimensional, ao desenvolver a Escala de Comportamentos de Cidadania Organizacional (ECCO), primeira escala brasileira voltada a medir comportamentos de cidadania no ambiente laboral.

A medida de Siqueira (1995) é composta por 18 itens, os quais foram testados mediante análise fatorial. Esta análise revelou a existência de cinco fatores, que aparecem de forma coerente com a teoria de Katz e Kahn (1974). Conforme Porto e Tamayo (2003), o instrumento desenvolvido por Siqueira (1995) tem adequada fundamentação teórica e tem sido utilizado em pesquisas, no entanto, os índices de confiabilidade dos seus fatores são baixos. Deste modo, fundamentados no instrumento de Siqueira (1995), Porto e Tamayo (2003) desenvolveram e validaram a Escala de Civismo nas Organizações (ECO), composta por 41 itens e cinco fatores, exibidos e definidos na Quadro 1. Observa-se que os autores utilizam o termo "civismo", sugerido por Siqueira (1995). Entretanto, na presente investigação optou-se por manter a expressão "comportamento de cidadania organizacional", visto que continua sendo a utilizada na literatura internacional e na maioria das pesquisas desenvolvidas no Brasil (ESTIVALETE; COSTA; ANDRADE, 2014).

Porto e Tamayo (2003) sinalizam que as dimensões da ECO representam as mesmas categorias propostas no estudo de Katz e Kahn (1974) e Siqueira (1995). Ressaltam, por fim, que todos os fatores da ECO apresentaram boa confiabilidade, sendo os valores dos Alphas de Cronbach superiores a 0,80 .

REAd | Porto Alegre - Vol. 23 - No Especial - Dezembro 2017 - p. 262-291 
Quadro 1 - Fatores da ECO

\begin{tabular}{|l|l|}
\hline \multicolumn{1}{|c|}{ Fatores } & \multicolumn{1}{|c|}{ Definições } \\
\hline Sugestões criativas ao sistema & $\begin{array}{l}\text { Representa comportamentos dos funcionários, de sugestão de novas } \\
\text { ideias à administração para beneficiar a organização. }\end{array}$ \\
\hline Proteção ao sistema & $\begin{array}{l}\text { Congrega itens sobre ações que visam zelar pelo patrimônio da } \\
\text { organização. }\end{array}$ \\
\hline $\begin{array}{l}\text { Criação de clima favorável à } \\
\text { organização no ambiente externo }\end{array}$ & $\begin{array}{l}\text { Diz respeito a comportamentos de divulgação das vantagens e méritos } \\
\text { da organização fora do ambiente de trabalho. }\end{array}$ \\
\hline Autotreinamento & $\begin{array}{l}\text { Reúne itens sobre comportamentos, dos funcionários, de busca de } \\
\text { cursos e eventos que melhorem a sua performance no trabalho. }\end{array}$ \\
\hline Cooperação com os colegas & $\begin{array}{l}\text { Agrega itens que refletem comportamentos de auxílio aos colegas de } \\
\text { trabalho visando o benefício da organização. }\end{array}$ \\
\hline
\end{tabular}

Fonte: Elaborado com base em Porto e Tamayo (2003).

\section{MÉTODO}

Com o intuito de atender ao objetivo delineado neste estudo, optou-se por realizar uma pesquisa de carácter descritivo. Em relação à estratégia de pesquisa, o estudo configura-se como estudo de caso, que, de acordo com Gil (2002), comporta uma análise profunda e exaustiva de um ou de poucos objetos, permitindo a formação de um conhecimento detalhado. Essa estratégia possibilita o entendimento de características significativas a respeito dos fenômenos em um contexto específico (YIN, 2010).

Assim, a organização escolhida para o cumprimento desta pesquisa é uma indústria fabricante de eletrodomésticos do Rio Grande de Sul, que está há 30 anos no mercado. Atualmente, a Empresa possui uma força de trabalho composta por 490 colaboradores que trabalham em $28.600 \mathrm{~m}^{2}$ de área construída na unidade da matriz. Os seus produtos, inteiramente fabricados no Brasil, são comercializados a nível nacional e, seguindo seu projeto de expansão, para outros 43 países. A sua atuação no mercado interno e externo ocorre nos seguintes segmentos: distribuidores, atacadistas, varejistas, lojistas e comércio em geral. A linha de produção é ampla e diversificada com ênfase em produtos como fogões a gás, fogões a lenha, cooktops, fornos elétricos, fogões industriais, refrigeradores e expositoras de bebidas e outros.

Sua missão é "Ser autêntica e surpreendente em todos os lares, superando as expectativas e facilitando a vida das pessoas.". Quanto à sua visão, afirma que espera "Ser reconhecida no mercado nacional e internacional pela autenticidade, qualidade e inovação dos produtos, consolidando a marca.”. Os valores organizacionais declarados pela Empresa são: Humildade e Simplicidade; Ética e Respeito; Superação e Integração da Equipe; Persistência e Atitude; Criatividade e Inovação.

REAd | Porto Alegre - Vol. 23 - No Especial - Dezembro 2017 - p. 262-291 
Destaca-se que a empresa possui de maneira bem definida as funções de seleção, de gerenciamento e de desenvolvimento do capital humano, consolidando políticas e práticas de gestão de pessoas no ambiente laboral. Dentre essas pode-se citar, por exemplo, o Programa de Ideias, que visa fornecer meios para que os colaboradores expressem suas ideias e sejam recompensados pela mesma, o Trabalho de Ergonomia, voltado à preocupação com o bemestar e a adequação das melhores condições de trabalho, e o Programa de Capacitação, destinado a disponibilizar oportunidades de desenvolvimento aos colaboradores.

Ressalta-se ainda que, por meio do Sistema de Gestão da Qualidade, a Empresa vem aprimorando seus processos para garantir a excelência em seus produtos e serviços e em consequência a conquista da satisfação de colaboradores, clientes e demais parceiros. Algumas de suas certificações foram o Troféu Prata no Prêmio Qualidade RS 2011, a Certificação na Portaria 371 do INMETRO, tanta na linha produtiva como nos seus produtos e, em 2013, o Certificado de Registro do Sistema de Gestão da Qualidade ISO 9001:2008.

A escolha de tal unidade de análise se deu de forma intencional, visto que se buscou selecionar um caso típico em relação aos fenômenos que se pretende estudar (YIN, 2010). Em linhas gerais, a opção por este caso deu-se também devido à acessibilidade da mesma, ao seu grande porte e a particularidade de ser a única do segmento no estado. Além disso, pode-se destacar a fase de expansão a qual se posiciona e sua gestão formalizada, com práticas pertinentes à concepção deste trabalho.

No que tange à abordagem do problema de pesquisa, o estudo configura-se pela utilização de uma combinação dos métodos quantitativo e qualitativo de coleta e análise de dados. A utilização do método misto, no entendimento de Goldenberg (2004), admite que o pesquisador possa cruzar as conclusões obtidas, de modo a conseguir maior confiança de que os dados não são produto de um procedimento específico ou de alguma situação particular. Ademais, contribui na compreensão de questões que podem não ser respondidas somente por uma das abordagens, à medida que fornece amplitude e profundidade à investigação e possibilita uma descrição mais rigorosa do fenômeno (CRESWELL, 2010). Para facilitar a compreensão, a Figura 1 apresenta o desenho de pesquisa.

No que se refere à etapa quantitativa desta pesquisa, partiu-se do total de 490 colaboradores, optando pela técnica de amostragem probabilística aleatória, sugerida por Lopes et al. (2008), com um nível de confiança de $95 \%$ e erro padrão de $5 \%$, de forma que se chegou a um resultado de 216 questionários. Todavia, obteve-se um retorno superior ao valor

REAd | Porto Alegre - Vol. 23 - No Especial - Dezembro 2017 - p. 262-291 
determinado pelo cálculo amostral, totalizando 302 respondentes (61,63\% da população).

Esta etapa da coleta de dados ocorreu por meio da aplicação de um questionário contendo a Escala de Civismo nas Organizações (ECO), formatada e validada por Porto e Tamayo (2003). A ECO contém 41 itens, disseminados em cinco fatores: Sugestões criativas ao sistema; Proteção ao sistema; Criação de clima favorável à organização no ambiente externo; Autotreinamento; e Cooperação com os colegas. Convém ressaltar que para avaliação dos itens é utilizada uma escala likert de 5 pontos (1=nunca; $2=$ quase nunca; $3=a ̀ s$ vezes; $4=$ quase sempre; $5=$ sempre).

Figura 1 - Desenho de pesquisa

\begin{tabular}{|c|c|c|}
\hline \multicolumn{1}{|c|}{ ESTUDO DE CASO: Indústria fabricante de eletrodomésticos } \\
$\begin{array}{c}\text { Quantitativa } \\
302\end{array}$ & $\begin{array}{c}\text { Comportamento de Cidadania } \\
\text { Organizacional }\end{array}$ & $\begin{array}{c}\text { Etapa } \\
\text { Qualitativa }\end{array}$ \\
$\begin{array}{c}\text { ECO (PORTO; TAMAYO, 2003) } \\
\text { questionários } \\
\text { aplicados a } \\
\text { colaboradores } \\
\text { de diferentes } \\
\text { níveis da }\end{array}$ & $\begin{array}{c}\text { Sugestões criativas ao sistema } \\
\text { Proteção ao sistema } \\
\text { Criação de clima favorável à } \\
\text { organização no ambiente externo } \\
\text { Autotreinamento } \\
\text { Cooperação com os colegas }\end{array}$ & com gestores. \\
\hline
\end{tabular}

Fonte: Elaborado pelos autores.

Após coletados, os dados foram transpostos para o software SPSS (Statistical Package for the Social Sciences), versão 20.0, o que corroborou para a mensuração, a organização e a análise das variáveis levantadas. Inicialmente, para traçar o perfil dos pesquisados, foram efetuadas análises estatísticas e de frequência relacionadas às variáveis sociodemográficas e profissionais pesquisadas. Para determinar se a percepção dos pesquisados difere quando consideradas às variáveis pessoais e profissionais realizaram-se testes T e ANOVA para amostras independentes. Em seguida, como técnica apropriada para obtenção dos construtos dos modelos estudados utilizou-se a análise fatorial. Para avaliar a confiabilidade dos fatores obtidos a partir da análise fatorial, foi empregado o indicador Alpha de Cronbach.

No que tange à etapa qualitativa, a amostra caracteriza-se em não probabilística intencional e por conveniência, que supõe um procedimento de seleção informal (SAMPIERI; COLLADO; LUCIO, 2006). Diante dessa perspectiva, foram realizadas 10 entrevistas semiestruturadas com gestores das diferentes áreas da Empresa, conforme sugestão da diretoria da Empresa e a disponibilidade dos pesquisados, até ser percebido o esgotamento das

REAd | Porto Alegre - Vol. 23 - No Especial - Dezembro 2017 - p. 262-291 
respostas, ou seja, quando elas tenderam a se repetir e novas entrevistas não ofereceriam um ganho qualitativo adicional para o entendimento do fenômeno pesquisado (MINAYO, 2010).

A opção de entrevistar os gestores deu-se, primeiramente, pela possibilidade de obter uma visão mais geral acerca dos CCO presentes no ambiente laboral investigado, visto que os mesmos tendem a ter condições de ponderar não apenas sob os seus comportamentos, mas sobre aquilo que captam nos indivíduos que gerenciam. Além disso, considerou-se o entendimento de Tamayo e Trócolli (2002), os quais sopesam que a organização não atua como uma entidade abstrata e sim por meio do comportamento individual de membros-chave, isto é, daqueles que ocupam posições de gerência ou liderança. Assim, a realização de entrevistas com os gestores contribui para a maior compreensão do fenômeno investigado.

Os questionamentos que compõem o instrumento utilizado nesta etapa buscam a percepção dos entrevistados quanto aos comportamentos de cidadania praticados na organização. O roteiro da entrevista foi composto por cinco questões abertas, arquitetadas a partir do modelo de Porto e Tamayo (2003), além de questões de perfil. Salienta-se que mediante a autorização de todos os participantes, as entrevistas foram gravadas e, a posteriori, transcritas para fins de análise do conteúdo coletado.

Para realizar a análise, as referidas entrevistas foram codificadas por temas, conforme a abordagem seletiva, sugerida por Van Manen (1990), na qual se destacam orações ou parte de orações que parecem ser temáticas da experiência vivida. Em síntese, os dados qualitativos foram analisados em três fases consideradas fundamentais (MINAYO, 2010), a pré-análise, a descrição analítica e a interpretação referencial.

\section{ANÁLISE DOS RESULTADOS}

A fim de identificar os comportamentos de cidadania organizacional predominantes no contexto organizacional estudado, a partir da visão de colaboradores e de gestores, apresentase nesta seção, em um primeiro momento, o perfil dos pesquisados. Após, exibe-se a análise quantitativa dos dados obtidos por meio da aplicação da ECO (PORTO; TAMAYO, 2003) aos colaboradores de diversas posições hierárquicas da Empresa. Em seguida, aborda-se a análise das entrevistas realizadas com os gestores, sobre questões relacionadas aos CCO praticados em sua organização. Por fim, há uma discussão conjunta dos resultados das análises quantitativas e qualitativas.

\subsection{PERFIL DOS PESQUISADOS}

REAd | Porto Alegre - Vol. 23 - No Especial - Dezembro 2017 - p. 262-291 
Em relação à amostra pesquisada, na etapa quantitativa, foram investigados 302 colaboradores pertencentes a diversas posições hierárquicas da Empresa pesquisada. Em conjunto, os dados da Tabela 1 e da Tabela 2 apresentam o perfil dos pesquisados.

Tabela 1 - Perfil dos pesquisados (idade)

\begin{tabular}{ccc}
\hline Variável & $\bar{x}($ anos $)$ & DP (anos) \\
\hline Idade & 32,67 & 10,270 \\
\hline & Fonte: dados da pesquisa.
\end{tabular}

A amostra foi composta por $74,8 \%$ de homens e $25,2 \%$ de mulheres, os quais possuem, em média, 32,67 anos. Tais resultados vão ao encontro ao apresentado no estudo econômico desenvolvido pela Federação das Indústrias do Rio Grande do Sul (FIERGS) em 2011, o qual demonstra que há um predomínio de trabalhadores do sexo masculino na Indústria de Material Elétrico do RS. Além disso, a mesma pesquisa destaca que os trabalhadores são jovens, com idade média de 32,6 anos, equivalente ao encontrado nesta pesquisa.

Quanto à escolaridade, a maior parte dos pesquisados possui ensino fundamental incompleto $(34,2 \%)$, seguido de ensino médio completo $(25,8 \%)$ e ensino fundamental completo $(14,9 \%)$. Esse resultado revela um cenário ainda um pouco diversificado em comparação com a perspectiva da FIERGS (2011), a qual relata que as indústrias do RS estão cada vez mais contratando trabalhadores melhores qualificados ou investindo em programas de qualificação, tendo $42,2 \%$ de sua força de trabalho com ensino médio completo.

Sobre o estado civil, constatou-se que $37,8 \%$ dos colaboradores são solteiros, sendo também significativa a parcela de casados $(33,4 \%)$ e dos que estão em uma união estável $(21,4 \%)$. Além disso, a maior parte dos pesquisados (57,0\%) não possui filhos, o que pode ser explicado pela idade média da amostra $(32,67$ anos) e o expressivo percentual de solteiros participantes da pesquisa. Ainda ressalta-se que, entre aqueles que possuem filhos (43,0\%), há a preponderância de apenas um filho $(55,4 \%)$.

A respeito das atividades profissionais, os dados da Tabela 3 e da Tabela 4 fornecem, em conjunto, o perfil dos pesquisados. Primeiramente, ao analisar o tempo de serviço, verificou-se que os colaboradores possuem em média 4,86 anos de atuação na Empresa. Esse índice pode ser considerado alto, visto que em média o trabalhador permanece empregado nesta indústria por 48 meses (FIERGS, 2011).

REAd | Porto Alegre - Vol. 23 - No Especial - Dezembro 2017 - p. 262-291 
Tabela 2 - Perfil dos pesquisados (sexo, escolaridade, estado civil, filhos e $\mathrm{n}^{\mathrm{o}}$ de filhos)

\begin{tabular}{|c|c|c|c|}
\hline Variáveis & $\begin{array}{l}\text { Pesquisados } \\
\end{array}$ & Frequência & $\%$ \\
\hline \multirow{2}{*}{ Sexo } & Masculino & 225 & $74,8 \%$ \\
\hline & Feminino & 76 & $25,2 \%$ \\
\hline \multirow{8}{*}{ Escolaridade } & Ensino Fund. Incompleto & 101 & $34,2 \%$ \\
\hline & Ensino Fund. Completo & 44 & $14,9 \%$ \\
\hline & Ensino Médio Incompleto & 18 & $6,1 \%$ \\
\hline & Ensino Médio Completo & 76 & $25,8 \%$ \\
\hline & Curso Técnico & 23 & $7,8 \%$ \\
\hline & Ensino Superior Incompleto & 27 & $9,2 \%$ \\
\hline & Ensino Superior Completo & 5 & $1,7 \%$ \\
\hline & Pós-Graduação & 1 & $0,3 \%$ \\
\hline \multirow{5}{*}{ Estado Civil } & Solteiro & 113 & $37,8 \%$ \\
\hline & Casado & 100 & $33,4 \%$ \\
\hline & Divorciado & 18 & $6,0 \%$ \\
\hline & Viúvo & 4 & $1,3 \%$ \\
\hline & União Estável & 64 & $21,4 \%$ \\
\hline \multirow{2}{*}{ Filhos } & Sim & 130 & $43,0 \%$ \\
\hline & Não & 172 & $57,0 \%$ \\
\hline \multirow{4}{*}{$\mathrm{N}^{\mathrm{o}}$ de Filhos } & Um & 72 & $55,4 \%$ \\
\hline & Dois & 44 & $33,8 \%$ \\
\hline & Três & 12 & $9,2 \%$ \\
\hline & Quatro & 2 & $1,5 \%$ \\
\hline
\end{tabular}

Fonte: dados da pesquisa.

Tabela 3 - Perfil das atividades profissionais dos pesquisados (tempo de empresa)

\begin{tabular}{ccc}
\hline Variável & $\bar{x}$ (anos) & Desvio (anos) \\
\hline Tempo de Empresa & 4,86 & 5,163
\end{tabular}

Fonte: dados da pesquisa.

Em relação à distribuição dos sujeitos pesquisados nos setores de atuação da Empresa, a maior parte está alocada no Setor Produtivo $(79,0 \%)$. De forma que, no que tange ao cargo ocupado, destacaram-se as funções ligadas a esse setor, sendo o maior percentual referente ao cargo de auxiliar de produção (34,9\%). Ressalta-se que todos os cargos da Empresa foram pesquisados.

Tabela 4 - Perfil das atividades profissionais dos pesquisados (setor de atuação e cargo ocupado)

\begin{tabular}{clcc}
\hline \multicolumn{1}{c}{ Variáveis } & \multicolumn{1}{c}{ Pesquisados } & Frequência & \% \\
\hline \multirow{3}{*}{ Setor de Atuação } & Produção & 237 & $79,0 \%$ \\
& Administrativo & 19 & $6,3 \%$ \\
\cline { 2 - 4 } & Engenharia & 13 & $4,3 \%$ \\
\cline { 2 - 4 } & Outros & 31 & $10,3 \%$ \\
& Auxiliar de Produção & 101 & $34,9 \%$ \\
\cline { 2 - 4 } & Serviços Gerais & 41 & $14,2 \%$ \\
\cline { 2 - 4 } Cargo Ocupado & Operador de Máquinas & 22 & $7,6 \%$ \\
\cline { 2 - 4 } & Pintor & 17 & $5,9 \%$ \\
\cline { 2 - 4 } & Montador & 14 & $3,8 \%$ \\
\cline { 2 - 4 } & Soldador & 10 & $29,1 \%$ \\
\cline { 2 - 4 } & Outros & 84 & \\
\hline
\end{tabular}

Fonte: dados da pesquisa.

REAd | Porto Alegre - Vol. 23 - No Especial - Dezembro 2017 - p. 262-291 
$\mathrm{Na}$ segunda etapa, a qualitativa, foram investigados gestores das diferentes áreas da Empresa, totalizando 10 entrevistados. Para garantir a confidencialidade e o anonimato, os gestores são tratados nesta pesquisa como G1 para o Gestor 1, G2 para o Gestor 2 e, assim, sucessivamente, conforme ilustra a Tabela 5, que contempla os dados de perfil dos entrevistados.

Tabela 5 - Perfil dos gestores entrevistados

\begin{tabular}{ccccccc}
\hline Entrevistado & Cargo Ocupado & $\begin{array}{c}\text { Idade } \\
\text { (anos) }\end{array}$ & Sexo & Escolaridade & $\begin{array}{c}\text { Tempo de } \\
\text { Empresa }\end{array}$ & $\begin{array}{c}\text { Tempo no } \\
\text { Cargo }\end{array}$ \\
\hline G1 & $\begin{array}{c}\text { Gestor de } \\
\text { Laboratórios }\end{array}$ & 38 & Masculino & Superior Completo & 17 anos & 11 anos \\
\hline G2 & Gestor de Manutenção & 28 & Masculino & Superior Incompleto & 10 anos & 9 anos \\
\hline G3 & Gestor de Segurança & 31 & Masculino & Curso Técnico & 5 meses & 5 meses \\
\hline G5 & Gestor de Engenharia & 32 & Masculino & Superior Completo & 17 anos & 7 anos \\
\hline G6 & Gestor de Vendas & 28 & Masculino & Superior Completo & 12 anos & 4 anos \\
\hline G7 & $\begin{array}{c}\text { Gestor da } \\
\text { Refrigeração }\end{array}$ & 31 & Masculino & Superior Completo & 11 anos & 7 anos \\
\hline G8 & Gestor de Marketing & 28 & Masculino & Superior Incompleto & 6 anos & 6 anos \\
\hline G9 & Gestor de Produção & 28 & Masculino & Superior Incompleto & 10 anos & 2 anos \\
\hline G10 & $\begin{array}{c}\text { Gestor de Pesquisa e } \\
\text { Desenvolvimento }\end{array}$ & 33 & Masculino & Superior Completo & 14 anos & 8 anos \\
\hline
\end{tabular}

Fonte: dados da pesquisa.

A análise da Tabela 5 permite identificar que a faixa etária dos gestores entrevistados varia de 27 a 38 anos, sendo são todos do sexo masculino. No que tange a escolaridade, a maioria possui curso superior completo. Quanto ao tempo de empresa, a maior parte dos entrevistados possui 10 ou mais anos de atuação e está há cinco anos ou mais na função atual.

\subsection{A VISÃO DOS COLABORADORES ACERCA DOS COMPORTAMENTOS DE CIDADANIA ORGANIZACIONAL}

Com o intuito de identificar a visão dos colaboradores acerca dos CCO optou-se por realizar, primeiramente, a técnica estatística da análise fatorial exploratória das variáveis que compõe a Escala de Civismo nas Organizações de Porto e Tamayo (2003). Assim, inicialmente foram utilizadas as 41 questões do instrumento para encontrar possíveis associações entre as variáveis, de maneira a agrupá-las em fatores comuns (HAIR et al., 
2009).

O emprego da análise fatorial requer a realização de testes estatísticos inicias que confirmem a adequação do conjunto de dados à referida técnica, como os testes de KaisorMeyer-Olkin (KMO) e de Esfericidade de Bartlett, aplicados neste estudo. De tal modo os resultados dos testes foram satisfatórios, uma vez que foi obtido para o KMO o coeficiente de 0,917 e o teste de Esfericidade de Bartlett apresentou valores favoráveis (sig 0,000). Ainda realizou-se a avaliação das comunalidades, na qual foram extraídas cinco questões do instrumento (ECO7, ECO15, ECO30, ECO31 e ECO36), as quais apresentaram índices inferiores a 0,5. Com as exclusões, o instrumento passou a ter 36 questões apropriadas para análise.

Os dados foram rotacionados novamente, obtendo-se um conjunto de variáveis que atende aos pressupostos necessários. Assim, após os testes iniciais, com o conjunto de dados considerado conforme definido, os dados referentes à ECO foram submetidos à análise fatorial de componentes principais, com normalização Kaiser e método de rotação varimax.

A resolução sobre o número de fatores deu-se por meio da consideração de dois critérios, sugeridos por Hair et al. (2009). O primeiro foi o do autovalor (eigenvalue), o qual corresponde ao quanto cada fator consegue explicar a variância e considera apenas os valores superiores a 1,0. O segundo critério refere-se ao percentual da variância explicada, o qual deve atingir valores de no mínimo $60 \%$ da variância acumulada (HAIR et al., 2009). A análise fatorial resultou em sete fatores, os quais explicam $61,54 \%$ da variância, sendo que o primeiro fator concentra 30,75\% da variância total. Ressalta-se, novamente, que o número de fatores não foi previamente definido, considerando-se apenas os fatores que obtiveram autovalores superiores a 1,0.

Em seguida, para medir a consistência interna dos fatores obtidos fez-se uso do teste de Alpha de Cronbach. Com exceção do fator 7, excluído por ser formado apenas por uma variável, os fatores 1, 2, 3, 4, 5 e 6 possuem índices de confiabilidade significativos. Observase, também, que, de acordo com a classificação sugerida por Hair et al. (2007), para o fator 1, o fator 2, o fator 3 e o fator 4 os índices obtidos apresentaram consistência interna muito boa, com alfas superiores a 0,8. Enquanto que para o fator 5 e o fator 6 os índices revelaram uma boa consistência interna, com alfas superiores a 0,7 .

Portanto, considerando a amostra pesquisada, os resultados na análise fatorial da ECO indicaram a presença de seis fatores, um fator a mais em relação ao modelo original desenvolvido por Porto e Tamayo (2003), totalizando 35 variáveis, as quais constatou-se 
possuírem uma carga fatorial superior a 0,4. Conforme apontam Hair et al. (2009) as cargas fatoriais acima de 0,3 atingem o nível mínimo, cargas fatoriais de 0,4 são mais importantes e as maiores que 0,5 são consideradas estatisticamente significativas.

Em linhas gerais, ressalta-se que foram mantidos todos os comportamentos de cidadania organizacional propostos por Porto e Tamayo (2003), embora tenha ocorrido a manifestação de um novo fator, denominado "Sugestões à gestão organizacional”, advindo da divisão de um dos fatores do modelo original ("Sugestões criativas ao sistema”). Além disso, a variável "Zelo pelo patrimônio desta organização" associada à dimensão "Proteção ao sistema" configurou-se em um fator distinto do original (“Criação de clima favorável à organização no ambiente externo"). Contudo, acredita-se que sua interpretação pode ter sido associada à preocupação com a marca e a imagem da Empresa no mercado, ativos intangíveis do patrimônio de grande importância (KOTLER; KELLER, 2012), demonstrando coerência entre esta e o sentido do fator.

Adverte-se que não foi possível encontrar alterações no número de fatores do modelo ECO em outros estudos, provavelmente devido ao número reduzido de estudos sobre o tema no Brasil (17 trabalhos), bem como a constatação de somente quatro pesquisas com a aplicação da ECO, segundo dados do levantamento realizado por Estivalete, Costa e Andrade (2014), do período de 2002 a 2012, nos principais eventos e periódicos nacionais de Administração. Contudo, essa condição encontra-se respaldada na revisão de literatura sobre o tema, a qual assinala para o caráter multidimensional do construto, em que não há um consenso quanto à quais e quantos fatores devem estar presentes no instrumento de avaliação (PODSAKOFF et al., 2000).

Tendo sido avaliada a análise fatorial, procedeu-se a verificação das médias e desvio padrão, tanto para as variáveis individuais quanto para os seis fatores encontrados, conforme pode ser visto na Tabela 6 .

Atendendo as variantes da escala de (1) nunca apresento o comportamento a (5) sempre apresento o comportamento, os resultados da Tabela 6 mostram que as variáveis de maiores médias de concordância entre os respondentes foram: (17) Procuro conhecer os meus equipamentos de trabalho; (6) Utilizo de forma adequada os equipamentos da organização; e (24) Uso com cuidado os equipamentos desta organização. Essas variáveis pertencem ao fator Proteção ao sistema, o qual, juntamente com o fator Cooperação com os colegas, apresentaram as maiores médias (4,59 e 4,26, respectivamente), considerando os seis fatores que representam os comportamentos de cidadania organizacional. Além disso, ressalta-se que

REAd | Porto Alegre - Vol. 23 - No Especial - Dezembro 2017 - p. 262-291 
a relevância dada a esses fatores é compartilhada entre os membros da organização, uma vez que os mesmos apresentam os dois menores desvios-padrão (0,787 e 0,944 , respectivamente).

Tabela 6 - Média e desvio padrão da ECO

\begin{tabular}{|c|c|c|c|}
\hline Var. & Descrição & Média & Desvio \\
\hline \multicolumn{4}{|c|}{ FATOR 4 - Proteção ao sistema } \\
\hline 16 & Zelo pela limpeza do ambiente de trabalho & 4,50 & 0,826 \\
\hline 17 & Procuro conhecer os meus equipamentos de trabalho & 4,66 & 0,681 \\
\hline 19 & Cuido com zelo dos equipamentos de trabalho & 4,56 & 0,866 \\
\hline 6 & Utilizo de forma adequada os equipamentos da organização & 4,64 & 0,789 \\
\hline 24 & Uso com cuidado os equipamentos desta organização & 4,60 & 0,772 \\
\hline TOTAL & & 4,59 & $\mathbf{0 , 7 8 7}$ \\
\hline \multicolumn{4}{|c|}{ FATOR 3 - Cooperação com os colegas } \\
\hline 40 & Ajudo colegas na resolução de problemas & 4,17 & 0,920 \\
\hline 38 & Colaboro quando colegas me pedem auxílio no trabalho & 4,51 & 0,828 \\
\hline 26 & Ofereço ajuda aos colegas que estejam sobrecarregados & 3,96 & 1,071 \\
\hline 37 & Ofereço apoio emocional a colegas com problemas pessoais & 3,98 & 1,127 \\
\hline 20 & Ofereço-me para ajudar um colega que está com dificuldade no trabalho & 4,49 & 0,792 \\
\hline 13 & Oriento um colega menos experiente no trabalho & 4,43 & 0,903 \\
\hline 21 & Repasso meus conhecimentos para os colegas de trabalho & 4,27 & 0,965 \\
\hline TOTAL & & 4,26 & $\mathbf{0 , 9 4 4}$ \\
\hline \multicolumn{4}{|c|}{ FATOR 1 - Criação de clima favorável à organização no ambiente externo } \\
\hline 27 & Dou informações boas sobre esta organização & 4,02 & 1,085 \\
\hline 39 & Defendo os produtos ou serviços desta organização & 4,07 & 1,067 \\
\hline 3 & Procuro defender a empresa que trabalho & 4,03 & 1,068 \\
\hline 23 & $\begin{array}{l}\text { Costumo passar a melhor das impressões para as pessoas que não conhecem } \\
\text { esta organização }\end{array}$ & 4,23 & 1,010 \\
\hline 41 & Zelo pelo patrimônio desta organização & 4,39 & 0,882 \\
\hline 12 & Costumo elogiar esta organização & 3,56 & 1,151 \\
\hline 28 & Informo sobre o papel desta organização na sociedade & 3,55 & 1,138 \\
\hline 18 & Descrevo as qualidades desta organização & 3,85 & 1,025 \\
\hline TOTAL & & $\mathbf{3 , 9 6}$ & $\mathbf{1 , 0 5 3}$ \\
\hline \multicolumn{4}{|c|}{ FATOR 2 - Sugestões criativas ao sistema } \\
\hline 2 & Contribuo com novas ideias para o melhor aproveitamento do ambiente físico & 3,39 & 1,105 \\
\hline 1 & Dou sugestões para resolver problemas no setor onde trabalho & 3,31 & 1,025 \\
\hline 4 & Contribuo com novas rotinas que possam melhorar o desempenho do meu setor & 3,17 & 1,220 \\
\hline 35 & Dou sugestão sobre a disposição do ambiente físico da minha área & 3,13 & 1,208 \\
\hline 8 & Realizo formas mais eficientes de fazer as tarefas & 3,69 & 1,085 \\
\hline 29 & Dou sugestão para melhorar o funcionamento do setor & 3,53 & 1,132 \\
\hline 11 & Dou sugestões sobre novos produtos e serviços & 2,67 & 1,190 \\
\hline TOTAL & & 3,27 & $\mathbf{1 , 1 3 8}$ \\
\hline \multicolumn{4}{|c|}{ FATOR 5 - Sugestões à gestão organizacional } \\
\hline 25 & Dou sugestão para melhorar a estrutura da organização & 2,64 & 1,363 \\
\hline 34 & Contribuo com sugestões para melhorar o gerenciamento da organização & 2,32 & 1,313 \\
\hline 22 & Penso em novos usos para equipamentos ociosos & 3,15 & 1,180 \\
\hline 32 & Dou novas ideias para aumentar a produtividade & 3,33 & 1,164 \\
\hline 14 & Repasso ideias novas sobre o meu trabalho nesta organização & 3,49 & 1,158 \\
\hline TOTAL & & 2,99 & 1,236 \\
\hline \multicolumn{4}{|c|}{ FATOR 6 - Autotreinamento } \\
\hline 5 & Frequento cursos de aperfeiçoamento profissional & 2,94 & 1,385 \\
\hline 33 & Busco cursos complementares que ampliem minha área de atuação & 3,04 & 1,282 \\
\hline 10 & Procuro frequentar cursos de reciclagem profissional & 2,94 & 1,380 \\
\hline TOTAL & & 2,97 & 1,349 \\
\hline
\end{tabular}

Fonte: dados da pesquisa. 
Esses resultados demostram que os comportamentos mais manifestados pelos colaboradores estão relacionados ao cuidado com o patrimônio da organização, sobretudo ao que se refere ao uso acertado e com cuidado dos equipamentos da organização, e a ajuda aos demais colaboradores, em especial quanto ao auxílio prestado a colegas inexperientes ou com dificuldades no trabalho. Para Coleman e Borman (2000), essa constatação mostra comportamentos de responsabilidade e dedicação para com o trabalho e com os colegas, suscitando a presença de atos cooperativos que vão além das expectativas. $\mathrm{O}$ escore alto no fator Proteção ao sistema pode estar relacionado à internalização e aceitação das regras e procedimentos adotados pelo sistema organizacional, de forma a promover o adequado funcionamento da organização, protegendo-a de prejuízos e perdas (HOCH, 2010).

Outro fator em proeminência, Cooperação com os colegas, segunda maior média obtida, conglomera comportamentos referentes a altruísmo e a ajuda aos outros (GEORGE; BRIEF, 1992). Essa dimensão inclui ações voluntárias de trabalhadores, demonstradas por meio de atitudes naturais de cortesia e encorajamento utilizadas para ajudar os colegas de trabalho, contribuindo desta forma na prevenção e na superação de problemas dentro da empresa (HOCH, 2010).

Em contrapartida, as variáveis que obtiveram as menores médias foram: (34) Contribuo com sugestões para melhorar o gerenciamento da organização; (25) Dou sugestão para melhorar a estrutura da organização, pertencentes ao fator Sugestões à gestão organizacional. Assim, em síntese, as evidências ora reunidas indicam que com os menores graus de prioridade encontram-se os fatores Autotreinamento $(2,97)$ e Sugestões à gestão organizacional $(2,99)$, sugerindo uma menor incidência de comportamentos relacionados à procura por cursos, treinamentos ou eventos que possam maximizar o desempenho do indivíduo e à apresentação de sugestões à administração que favoreçam toda a organização.

Resultados semelhantes foram verificados no estudo de Jardim (2009), por meio da investigação de colaboradores pertencentes à organização judiciária mineira. Em síntese, Proteção ao sistema foi evidenciada como a dimensão mais importante, seguida por Cooperação com os colegas. Por outro lado, os fatores Criação de clima favorável à organização no ambiente externo, Autotreinamento e Sugestões criativas ao sistema foram, nessa ordem, as próximas dimensões na classificação de importância. Outra pesquisa que obteve achados aproximados foi realizada por Santos (2009), a qual investigou a percepção de colaboradores de um hospital universitário.

Cabe destacar que os resultados obtidos nesta etapa da pesquisa de campo REAd | Porto Alegre - Vol. 23 - No Especial - Dezembro 2017 - p. 262-291 
potencializam os aspectos associados, principalmente, à proteção ao sistema, a cooperação com colegas e a criação de clima favorável à organização no ambiente externo, fatores que obtiveram as maiores médias na aplicação da ECO. Esses achados corroboram a natureza benéfica desses tipos básicos de comportamentos para o sistema organizacional, estabelecida desde os estudos de Katz e Kahn (1974), e reforçam que os CCO tendem a incluir ações que visam zelar pelo patrimônio da organização, auxiliar os colegas de trabalho e divulgar os méritos da organização fora do ambiente de trabalho.

Ainda, no intuito de testar as diferenças estatísticas significantes entre as médias das respostas relacionadas aos $\mathrm{CCO}$, determinou-se como método a análise da variância para comparar as amostras de uma variável dependente. Ao ponderar o gênero dos pesquisados, pode-se afirmar, com $95 \%$ de confiança, que as colaboradoras do sexo feminino atribuem média superior ao fator Proteção ao sistema $(4,73)$ se comparadas aos do sexo masculino $(4,51)$. Todavia, os colaboradores do sexo masculino atribuem médias superiores aos fatores Sugestões criativas ao sistema (3,33), Sugestões à gestão organizacional (3,09) e Autotreinamento $(3,10)$ se comparados as do sexo feminino que conferem médias de 3,07; 2,73; e 2,64, para as respectivas dimensões.

Também, observou-se que os colaboradores que possuem filhos atribuem médias superiores $(4,10)$ ao comportamento Criação de clima favorável à organização no ambiente externo se comparado aos que não possuem filhos $(3,82)$. Em contrário, quando se trata de Autotreinamento, os colaboradores que não possuem filhos atribuem médias superiores $(3,10)$ se comparado aos que possuem filhos $(2,83)$.

Dando seguimento, foram realizados testes paramétricos (ANOVA) a fim de testar a existência de diferenças entre os fatores de CCO quando consideradas as variáveis escolaridade, estado civil, setor e cargo. Neste sentido, percebe-se que, considerando a escolaridade dos investigados, obteve-se diferença significativa (Sig.< 0,05) para as percepções dos fatores Sugestões criativas ao sistema, Sugestões à gestão organizacional e Autotreinamento. Em todos esses fatores a maior média obtida foi designada por colaboradores que possuem curso técnico $(3,76 ; 3,51$; e 3,80, respectivamente). Por outro lado, em média, os colaboradores com um menor nível de escolaridade, ensino médio incompleto para Sugestões criativas ao sistema $(2,92)$ e Sugestões à gestão organizacional $(2,71)$ e ensino fundamental incompleto para Autotreinamento $(2,58)$, apontaram a menor incidência desses comportamentos na Empresa.

Ao tomar as percepções dos colaboradores considerando o seu estado civil, constatou-

REAd | Porto Alegre - Vol. 23 - No Especial - Dezembro 2017 - p. 262-291 
se que diferença significativa de média apenas para a dimensão Criação de clima favorável à organização no ambiente externo, para qual foram atribuídas médias estatisticamente superiores por colaboradores divorciados $(4,41)$ e as menores médias apresentadas pelos viúvos $(3,70)$. Por outro lado, quando avaliadas as variáveis setor e cargo, houve diferenças significativas de médias para todos os fatores pesquisados.

Primeiramente, a análise para setor revelou que nas dimensões Proteção ao sistema, Criação de clima favorável à organização no ambiente externo e Sugestões à gestão organizacional as maiores médias foram postas pelos colaboradores do Setor Administrativo $(4,76 ; 4,51$; e 3,58, respectivamente) e, nas demais, Cooperação com os colegas, Sugestões criativas ao sistema e Autotreinamento, pelos colaboradores do Setor de Engenharia (4,54; 4,03; e 3,95, respectivamente). As menores médias obtidas em todos os fatores advieram da percepção dos colaboradores do Setor de Produção $(4,54 ; 3,84 ; 2,89 ; 4,17 ; 3,13$; e 2,87, respeitando a mesma ordem no qual os fatores foram citados em relação às maiores médias).

Finalmente, quanto ao cargo, às médias mais elevadas para Proteção ao sistema $(4,94)$ e Criação de clima favorável a organização no ambiente externo $(4,39)$ foram dadas pelos colaboradores com o cargo de Soldador. Já para Cooperação com os colegas $(4,47)$, Sugestões criativas ao sistema $(3,80)$, Sugestões à gestão organizacional $(3,47)$ e Autotreinamento $(3,59)$

pelos colaboradores cujos cargos foram agrupados na denominação "Outros", como, por exemplo, aqueles pertencentes ao Setor Administrativo e de Engenharia. Quanto às médias mais baixas, para todos os fatores, essas foram sinalizadas pelos colaboradores que exercem a função de Serviços gerais $(4,43 ; 3,71 ; 4,03 ; 2,80 ; 2,54$; e 2,55, em acordo com a ordem utilizada para citar as maiores médias).

\subsection{A VISÃO DOS GESTORES ACERCA DOS COMPORTAMENTOS DE CIDADANIA ORGANIZACIONAL}

A fim de ampliar a compreensão acerca dos achados da pesquisa quantitativa, concretizou-se uma fase qualitativa com a participação de colaboradores que ocupam cargos de gestão na empresa foco deste estudo. Em relação aos comportamentos de cidadania organizacional, de um modo geral, os entrevistados percebem a existência de todos os tipos de comportamentos, conforme pode ser visto no Quadro 2.

REAd | Porto Alegre - Vol. 23 - No Especial - Dezembro 2017 - p. 262-291 
Quadro 2 - Visão dos gestores em relação aos comportamentos de cidadania organizacional praticados na empresa

\begin{tabular}{|c|c|c|c|c|c|}
\hline \multirow[b]{2}{*}{ Entrevistado } & \multicolumn{5}{|c|}{ Comportamento de Cidadania Organizacional } \\
\hline & $\begin{array}{l}\text { Sugestões } \\
\text { criativas } \\
\text { ao sistema }\end{array}$ & $\begin{array}{c}\text { Proteção ao } \\
\text { sistema }\end{array}$ & $\begin{array}{c}\text { Criação de clima } \\
\text { favorável à organização } \\
\text { no ambiente externo }\end{array}$ & Autotreinamento & $\begin{array}{c}\text { Cooperação } \\
\text { com os } \\
\text { colegas }\end{array}$ \\
\hline G1 & $\mathrm{X}$ & $\mathrm{X}$ & $\mathrm{X}$ & $\mathrm{X}$ & $\mathrm{X}$ \\
\hline G2 & $\mathrm{X}$ & $\mathrm{X}$ & & $\mathrm{X}$ & $\mathrm{X}$ \\
\hline G3 & & $\mathrm{X}$ & & $\mathrm{X}$ & $\mathrm{X}$ \\
\hline G4 & $\mathrm{X}$ & $\mathrm{X}$ & $\mathrm{X}$ & $\mathrm{X}$ & $\mathrm{X}$ \\
\hline G5 & $\mathrm{X}$ & $\mathrm{X}$ & $\mathrm{X}$ & $\mathrm{X}$ & $\mathrm{X}$ \\
\hline G6 & $\mathrm{X}$ & $\mathrm{X}$ & $\mathrm{X}$ & & $\mathrm{X}$ \\
\hline G7 & $\mathrm{X}$ & $\mathrm{X}$ & $\mathrm{X}$ & $\mathrm{X}$ & $X$ \\
\hline G8 & & $X$ & $\mathrm{X}$ & & $X$ \\
\hline G9 & $\mathrm{X}$ & $\mathrm{X}$ & $\mathrm{X}$ & & $\mathrm{X}$ \\
\hline G10 & $X$ & $X$ & $X$ & $X$ & $\mathrm{X}$ \\
\hline
\end{tabular}

Fonte: dados da pesquisa.

No entanto, os gestores compreendem que há uma maior incidência de comportamentos relacionados à Proteção ao sistema e Cooperação com os colegas, tendo em vista que foram observadas algumas divergências em relação aos outros tipos de CCO. Para Porto e Tamayo (2005), isto demostra a predominância da manifestação de ações que visem cuidar do patrimônio da empresa, contribuindo dessa forma para evitar o desperdício de materiais e zelar pelos equipamentos, e que prezem por atividades de cooperação com os demais membros.

Em relação à Proteção ao sistema, todos os gestores relataram que o grupo de trabalho manifesta comportamentos de zelo pelo patrimônio da organização. Os entrevistados ressaltaram, principalmente, o trabalho de conscientização efetivado pela própria Empresa no sentido de incrementar esses comportamentos, por meio de treinamentos e programas de qualidade, conforme pode ser evidenciado nas ponderações dos gestores G1, G2, G5 e G7.

Os colaboradores têm um cuidado com o que pertence a empresa e muito disso é graças aos próprios treinamentos e instruções de trabalho onde se passa como deve ser feito o manuseio dos equipamentos, os cuidados que se deve ter durante o uso e todas as questões de segurança também. (Entrevistado G1)

O meu setor já é digamos pra cuidar de grande parte do bem da empresa, então temos uma equipe que preza por isso. Uma parte vem do próprio colaborador, mas a outra é de um trabalho de conscientização também porque a gente pede pro pessoal colaborar com questão de separação de lixo, não sujar paredes, manter tudo organizado e em condições de uso. (Entrevistado G2)

REAd | Porto Alegre - Vol. 23 - No Especial - Dezembro 2017 - p. 262-291 
Eu não vejo problemas de depreciação de patrimônio, pelo contrário vejo conscientização do pessoal nesse sentido de cuidado com a empresa. Não tenho reclamação desse ponto da nossa equipe e pelo o que eu vejo em toda a empresa é assim até pelos próprios programas de qualidade que a empresa aplica já vão criando na cultura, então a gente vê muitos funcionários que cuidam das cadeiras, dos equipamentos, fazem a limpeza das mesas também, sempre focando pra manter um ambiente de trabalho bom. (Entrevistado G5)

Os colaboradores têm noção do custo alto caso um equipamento estrague ou quebre, sabem que precisam praticar a preservação do ambiente de trabalho. Eles cuidam também porque entendem que assim pode ser adquirido um a mais daqui a pouco um equipamento mais moderno pra poder agregar a produção e até pra facilitar as operações que eles fazem. (Entrevistado G7).

Como observado no Quadro 2, a Cooperação com os colegas foi um comportamento igualmente predominante na visão de todos os entrevistados. Os relatos dos gestores enaltecem o trabalho em equipe, principalmente refletido no bom relacionamento e nas ações de auxílio entre colegas de trabalho. Destacam, ainda, ser um comportamento presente em toda a Empresa, como demonstra as falas de G1, G3 e G8.

O trabalho em equipe aqui é excelente, é uma coisa incentivada pela empresa também. $O$ pessoal se dá bem uns com os outros e quando tem algo que alguém precisa há um espirito de ajuda, cooperação, de tentar solucionar os problemas juntos. (Entrevistado G1)

Existem comportamentos de cumplicidade aqui de um tendo e querendo colaborar com o outro e isso não importa o nível, a hierarquia. (Entrevistado G3)

Geralmente a nossa equipe tá sempre unida tentando um ajudar o outro. E não vejo isso apenas no meu departamento, pois trabalho numa sala que a maioria do pessoal é de outro setor, mas o que importa é que a gente presta serviço em conjunto, porque um precisa de outro. A ajuda é bem presente, todo mundo é aberto para contribuir com o outro como pode. (Entrevistado G8)

Conforme Santos (2011), é essencial a compreensão por parte dos líderes sobre a preocupação com a humanização do trabalho por meio do contato, da cooperação e da prevalência das relações sobre as tarefas. Desta forma, explica a autora, compreende-se que os

REAd | Porto Alegre - Vol. 23 - No Especial - Dezembro 2017 - p. 262-291 
$\mathrm{CCO}$, sobretudo os ligados a comportamentos de interajuda e de respeito pelos outros, sejam especialmente elevados.

A respeito de Sugestões criativas ao sistema, os resultados indicaram algumas divergências na exposição dos entrevistados. Para a maioria dos gestores, a liberdade de fornecer sugestões à administração é percebida pelos colaboradores, os quais se sentem a vontade para expor suas opiniões, como evidencia os relatos de G6 e G10.

Todos têm liberdade para expressar as suas opiniões e sinto que os colaboradores sentem vontade de trocar ideia. No caso dos colaboradores que tenho mais proximidade faço questão de deixar claro que quem tem alguma opinião ou sugestão pode falar abertamente não tem problema nenhum e isso tem ocorrido e funcionado bem. (Entrevistado G6)

Tentamos trabalhar sempre, digamos assim, sem impor nada sabe mais em forma de uma parceria. Assim a maioria dos colaboradores acaba contribuindo, pois sabe que aceitamos sugestões. Eles também passaram a ver que quem realiza a atividade tem ideias melhores do que a pessoa que está só gerenciando. (Entrevistado G10)

Contudo, para dois dos 10 gestores entrevistados, este é um comportamento que ainda precisa ser desenvolvido no ambiente laboral. Uma vez que, apesar da flexibilidade da Empresa, percebem falta de iniciativa e, na maioria das vezes, um sentimento de incapacidade de contribuir, por ausência de experiência ou conhecimento, por parte dos colaboradores. Os depoimentos de G3 e G8 ilustram essa constatação.

É complicado, a Empresa é flexível para receber sugestões a questão é que muitas vezes as pessoas não tem a iniciativa de querer contribuir ou até mesmo não se sentem à vontade ou preparadas, por acharem que tem pouco conhecimento. (Entrevistado G3)

A gente trabalha o máximo possível com os colaboradores para mostrar pra eles que eles são importantes na organização não importando o cargo. Hoje até mesmo nos treinamentos tentamos fazer de uma maneira que o operador se sinta mais a vontade e saiba o que a empresa espera de cada um. Só que não é uma ação recorrente, vejo que muitos ainda não participam e acho que não falam e sugerem mais pelo sentimento de que não tem experiência, habilidade, conhecimento, essas coisas. (Entrevistado G8)

REAd | Porto Alegre - Vol. 23 - No Especial - Dezembro 2017 - p. 262-291 
Quando questionados sobre a Criação de clima favorável à organização no ambiente externo, os gestores expuseram suas percepções referentes à suas experiências pessoais, sem generalizações ao grupo de trabalho, já que este comportamento espontâneo relaciona-se a impossibilidade de prever e de controlar a visibilidade humana (PORTO; TAMAYO, 2003). A análise dos relatos dos entrevistados indicou duas correntes distintas de comportamentos. A primeira, composta pela maioria dos gestores, revela a incidência deste tipo de comportamento, como explanam G9 e G10.

Eu sempre gosto de falar de uma maneira boa, eu trabalho aqui há anos, eu tenho que defende isso aqui. Eu sei que esse é meu ganha pão e é muito bom estar aqui, a verdade é essa. (Entrevistado G9)

Geralmente quando a gente conversa com pessoas de fora $e$ fala do nosso trabalho, elas ficam surpresas né, porque a empresa ela tem uma organização bem bacana assim, que tu não vê na região. Ela tem uma característica um pouco diferente, mais verticalizada, então os processos são tudo internos e essa gestão impressiona bastante, então procuro sempre evidenciar isso quando falo da empresa. (Entrevistado G10)

Em dissonância, a segunda corrente é composta por gestores que dizem preferir não comentar a respeito da organização e do trabalho no ambiente externo, seja referindo-se a aspectos positivos quanto a negativos. Os relatos de G2 e G3 ilustram essa percepção.

Não acontece muito de eu falar da organização fora daqui, seja em relação a coisas boas, seja em relação a coisas ruins. Tento dissociar o pessoal e o profissional, falo quando é preciso claro. Acho que falo mais da minha profissão no geral mesmo. (Entrevistado G2).

Essa pergunta não me cabe muito, porque eu não falo de trabalho fora daqui. Caso entrem no assunto, ou estejam falando da empresa, eu não costumo falar, não dou características porque assim eu separo bem mesmo, saio pra fora do portão não falo de empresa não falo de trabalho. (Entrevistado G3)

Por fim, sobre o Autotreinamento, os discursos dos entrevistados também apresentaram alguns pontos divergentes. Para a maioria dos gestores, existe uma busca constante por aperfeiçoamento por parte dos colaboradores, por meio da participação em capacitações e, em alguns casos, pela retomada de seus estudos, como explanam G4 e G5.

REAd | Porto Alegre - Vol. 23 - No Especial - Dezembro 2017 - p. 262-291 
Dentro das nossas disponibilidades, acho que a equipe tenta se manter estudando, buscando curso de aperfeiçoamento $e$ aproveita ao máximo as oportunidades de treinamentos dentro da empresa. (Entrevistado G4)

As pessoas aqui dentro têm uma vontade de fazer jus ao cargo, pelo menos àqueles interessados, comprometidas mesmo. Muitas vezes acontece do próprio grupo nos propor, solicita algo, um treinamento, um curso, uma troca entre colegas para aprender mais e tem muita gente que voltou a estudar, tanto por vontade própria como por estímulo e ajuda da empresa. (Entrevistado G5)

Entretanto, para três dos 10 gestores participantes desta pesquisa, o comportamento de Autotreinamento ainda é um aspecto a desenvolver dentro do ambiente de trabalho. Isto porque, segundo os entrevistados, há pouca iniciativa na busca por capacitações por parte dos colaboradores, a qual pode estar atrelada ao perfil da força de trabalho, como destacam as falas de G6 e G9.

Eu vejo que isso é um ponto que pode melhorar, tanto a inciativa dos colaboradores em quererem se aperfeiçoar, acho que ainda falta uma vontade própria deles. Só que também quanto à questão de levantamento de capacitação por nossa parte, por parte da empresa, ou até mesmo de uma maior ajuda de custo pra cursos e estudos. (Entrevistado G6)

A grande maioria participa dos cursos e eventos quando é solicitado, sem generalizações, mas às vezes pelo perfil, pelo tipo de trabalho que exercem, as pessoas acabam se acomodando, não enxergam muitas perspectivas e fazem o básico quando delimitado pela empresa mesmo. (Entrevistado G9).

Ao concluir, sintetiza-se que houve uma concordância entre os gestores quanto aos comportamentos de cidadania organizacional praticados pelos colaboradores no ambiente laboral investigado. Porém, em alguns casos, quando se tratou de comportamentos relacionados a Sugestões criativas ao sistema, a Criação de clima favorável à organização no ambiente externo e ao Autotreinamento, os entrevistados demonstraram algumas dissensões, o que pode indicar que estes aspectos podem ser mais desenvolvidos pelos colaboradores.

REAd | Porto Alegre - Vol. 23 - No Especial - Dezembro 2017 - p. 262-291 


\subsection{ANÁLISE CONJUNTA: ASSOCIANDO AS VISÕES DE COLABORADORES E GESTORES ACERCA DO COMPORTAMENTO DE CIDADANIA ORGANIZACIONAL}

O emprego dos dois campos das análises de dados, o quantitativo e o qualitativo, permitiu ampliar a compreensão acerca dos tipos de comportamento de cidadania organizacional predominantes na organização estudada, de acordo com a visão de seus colaboradores e gestores. Com isto, em linhas gerais, desprendeu-se que os dados obtidos na etapa quantitativa foram ratificados por meio das entrevistas com os gestores da Empresa.

A concordância por parte de todos os entrevistados em relação ao predomínio dos atos que envolvem Proteção ao sistema e Cooperação com os colegas apoiou os resultados alcançados na aplicação da ECO na etapa quantitativa desta pesquisa. Em um primeiro momento, evidenciou-se que, para os colaboradores, os itens de maior concordância pertenciam ao fator Proteção ao sistema, como a afirmativa "Procuro conhecer os meus equipamentos de trabalho". Posteriormente, os relatos dos gestores reforçaram a visão acerca da primazia na manifestação de atos que envolvem zelo pelo patrimônio da organização, alavancados, segundo eles, pelas ações de conscientização idealizadas pela Empresa.

Outro aspecto que apoia os resultados quantitativos refere-se ao destaque dado, também, ao comportamento Cooperação com os colegas, tanto pelos colaboradores quanto pelos gestores entrevistados. Os colaboradores ressaltaram exibir atos de auxílio e orientações aos colegas quando solicitados ou em casos de dificuldades no trabalho, o que foi confirmado pelos gestores, os quais destacaram perceber trabalho em equipe no ambiente de trabalho, conjecturado no bom relacionamento e na assistência entre colegas.

Ainda, as evidências reunidas no exame quantitativo indicaram menores níveis de manifestação de Autotreinamento e Sugestões à gestão organizacional, devido às suas baixas médias, segundo a visão dos colaboradores. Na etapa qualitativa, a percepção dos gestores apresentou algumas inconsonâncias para aspectos relacionados a estes fatores, bem como para a Criação de clima favorável à organização no ambiente externo. Todavia, para a maioria dos entrevistados, estes são comportamentos recorrentes nos membros da organização, o que acaba não contribuindo no esclarecimento dos resultados obtidos na etapa quantitativa.

\section{CONSIDERAÇÕES FINAIS}

REAd | Porto Alegre - Vol. 23 - No Especial - Dezembro 2017 - p. 262-291 
Para o cumprimento do propósito deste estudo, primeiramente, foram aplicados questionários aos colaboradores de diversas posições hierárquicas, tendo como base o modelo ECO de Porto e Tamayo (2003), o que possibilitou identificar a visão dos mesmos em relação aos CCO predominantes no contexto organizacional examinado. Após, com o intuito de ampliar a compreensão e identificar a visão dos gestores sobre os CCO, realizaram-se entrevistas com 10 gestores da Empresa.

Em suma, averiguou-se que os comportamentos de Proteção ao sistema e de Cooperação com os colegas foram os indicados pelos colaboradores como os mais presentes no contexto organizacional investigado. De igual modo, todos os gestores entrevistados revelaram uma concordância em relação ao predomínio desses comportamentos, apoiando os resultados alcançados na aplicação da ECO.

Em contrapartida, as evidências reunidas indicaram que, na visão dos colaboradores, o Autotreinamento e o comportamento de Sugestão à gestão organizacional são os menos praticados no ambiente de trabalho. Contudo, nas entrevistas, apesar de algumas dissensões nas falas dos participantes, a maioria apontou esses comportamentos como recorrentes nos membros da organização, ilustrando uma disparidade entre as concepções dos colaboradores e dos gestores.

Em linhas gerais, considerando todas as percepções obtidas, pode-se observar que várias das dimensões tradicionalmente definidas para os comportamentos de cidadania (PODSAKOFF et al., 2000; PORTO; TAMAYO, 2003; SAHIN, 2013) foram identificadas nos colaboradores pesquisados, o que indica que na empresa há cidadãos organizacionais. Ao sopesar as condutas mais manifestadas, parece haver uma relação de identidade e preocupação entre o profissional e a empresa pesquisada, reveladas na presença de atos de proteção ao sistema e extensivos a defesa da imagem da organização na sociedade. Também, esses profissionais orientam-se para seus pares, exibindo diversos comportamentos arrolados ao auxílio aos colegas de trabalho.

Por outro lado, as condutas indicadas como menos manifestadas, principalmente por aqueles colaboradores não gestores, despontam que ainda não há um empenho suficiente no que se refere a busca por aperfeiçoamento profissional. Tal constatação pode atrelar-se ao fato dos mesmos também não perceberem de forma tão significativa a emissão de sugestão capazes de contribuir para o melhoramento do sistema.

Diante desses resultados, verifica-se que o objetivo geral proposto para esta pesquisa foi alcançado. Assim, em termos gerais, acredita-se que esta investigação pode colaborar com

REAd | Porto Alegre - Vol. 23 - No Especial - Dezembro 2017 - p. 262-291 
os estudos no campo de comportamento organizacional, em específico, a respeito dos comportamentos de cidadania organizacional, posto que há diversos aspectos pertinentes ao tema ainda pouco explorados (CHOW; LAI; LOI, 2015). A relevância dos resultados obtidos neste estudo permitiu ampliar a reflexão acerca das perspectivas individuais e relacionais, as quais permeiam o construto, possibilitando um olhar mais profundo sobre o fenômeno investigado.

Especialmente, considera-se que este estudo mostrou-se apropriado na exposição de uma fundamentação que sintetiza diferentes abordagens e definições do construto, além de investigar as suas múltiplas dimensões em um contexto diversificado, por meio de uma investigação por método misto. Sobre esse último, salienta-se que a investida numa pesquisa de natureza quali-quanti representa uma adequada iniciativa, posto que na literatura nacional, revisam Cantal, Borges-Andrade e Porto (2015), a totalidade dos artigos sobre CCO publicados nos últimos anos descreveu técnicas quantitativas. Ademais, desenvolver um estudo com foco exclusivo nos comportamentos de cidadania organizacional é mais do que uma manifestação de sua relevância, é uma tentativa de fomentar a área, principalmente no Brasil, no qual a produção ainda é pequena e inconsistente (CANTAL; BORGESANDRADE; PORTO, 2015).

Como fatores limitantes da pesquisa, evidencia-se que o estudo em questão aborda aspectos comportamentais, os quais possuem caráter subjetivo e de difícil controle (GOMES, 2014). Neste sentido, para a consecução dos objetivos, mensurou-se CCO por meio de um conjunto de itens que representam traços individuais, como altruísmo, virtudes cívicas e esportividade, conforme sugerem as medidas empíricas mais comuns. No entanto, sabe-se que, sendo um padrão comportamental (KATZ; KAHN, 1974; SMITH; ORGAN; NEAR, 1983), representam condutas dirigidas à organização empregadora, podendo apresentar um conjunto ainda mais diferenciado de atos, os quais possivelmente podem não ter sido contemplados nesta pesquisa.

Destaca-se também a medida dos CCO realizada, exclusivamente, a partir da percepção dos colaboradores e gestores. Mais do que isso, um limite do estudo pode estar relacionado ao fato dos colaboradores, na etapa quantitativa do estudo, terem realizado autorrelatos de seus comportamentos, enquanto os gestores, na etapa qualitativa, ponderaram de uma forma mais abrangente sobre as condutas de cidadania organizacional presentes no ambiente laboral.

Outros aspectos que podem ser considerados refere-se ao número de entrevistados na

REAd | Porto Alegre - Vol. 23 - No Especial - Dezembro 2017 - p. 262-291 
etapa qualitativa, o qual pode não ter expressado com perfeita fidedignidade a percepção dos gestores, e a própria subjetividade da coleta, registro e análise das informações obtidas através das entrevistas (YIN, 2010), fato inerente à natureza do processo de comunicação, em que os procedimentos de codificação e decodificação da informação passam pelas experiências prévias do entrevistador e entrevistados.

Portanto, para pesquisas futuras, sugere-se o emprego de uma abordagem longitudinal, a qual permitiria uma visão mais densa do tema em pauta. Além disso, um maior aprofundamento pode ser obtido com a agregação de outras técnicas de coleta de dados, como a observação, para uma avaliação mais objetiva dos CCO.

Cabe, também, a realização de estudos para investigar as múltiplas dimensões do comportamento de cidadania organizacional em contextos difersificados. E, por fim, recomenda-se que tal linha de investigação prossiga buscando identificar diferenças nos significativos antecedentes e consequentes dos diferentes tipos de CCO. Sendo assim, sugerem-se estudos que articulem o fenômeno com outras variáveis, como os valores humanos, a personalidade, os estilos de lideranças, a identificação social e organizacional, o envolvimento com o trabalho etc.

\section{REFERÊNCIAS}

CANTAL, C.; BORGES-ANDRADE, J. E.; PORTO, J. B. Cooperação, comportamentos proativos ou simplesmente cidadania organizacional? Uma revisão da produção nacional na área. Revista Psicologia: Organizações e Trabalho, v. 15. n. 3, p. 286-297, 2015.

CHOW, C. W. C.; LAI, J. Y. M.; LOI, R. Motivation of travel agents' customer service behavior and organizational citizenship behavior: The role of leader-member exchange and internal marketing orientation. Tourism Management, v. 48, p. 362-369, 2015.

COLEMAN, V. I.; BORMAN, W. C. Investigating the underlying structure of the citizenship performance domain. Human Resource Management Review, v. 10, n. 1, p. 25-44, 2000.

CRESWELL, J. W. Projeto de pesquisa: métodos qualitativo, quantitativo e misto. 3. ed. Porto Alegre: Artmed, 2010.

CRUZ JÚNIOR, J. B. da. Repensando as funções do executivo. In: LANER, A. S.; CRUZ JÚNIOR, J. B. da. (Orgs.) Repensando as organizações: da formação à participação.

Florianópolis: Fundação Boiteux, 2004. p. 363-387.

ESTIVALETE, V. de F. B.; COSTA, V. F.; ANDRADE, T. Organizational citizenship

REAd | Porto Alegre - Vol. 23 - No Especial - Dezembro 2017 - p. 262-291 
behavior: a comparative study between brazilian and international scientific Output from 2002 to 2012. Business and Management Review, v. 4, n. 3, p. 427-441, 2014. FEDERAÇÃO DAS INDÚSTRIAS DO RIO GRANDE DO SUL. Fotografia do mercado de trabalho 2011. Porto Alegre: Unidade de Estudos Econômicos/FIERGS, 2011. GEORGE, J. M.; BRIEF, A. P. Feeling good-doing good: A conceptual analysis of the mood at work-organizational spontaneity relationship. Psychological Bulletin, v. 112, n. 2, p. 310 329, 1992.

GIL, A. C. Como elaborar projetos de pesquisa. 4. ed. São Paulo: Atlas, 2002.

GOLDENBERG, M. A arte de pesquisar: como fazer pesquisa qualitativa em ciências sociais. 8 ed. Rio de Janeiro: Record, 2004.

GOMES, A. C. P. et al. Cidadania e cidadania organizacional: questões teóricas e conceituais que cercam a pesquisa na área. Estudos e Pesquisa em Psicologia, v. 14, n. 3, p. 711-731, 2014.

GOMES, J. S. Controle de gestão comportamental: textos e casos. São Paulo: Atlas, 2014. HAIR, J. F. et al. Fundamentos de métodos de pesquisa em administração. São Paulo: Bookman, 2007.

HAIR, J. F. et al. Análise multivariada de dados. 6. ed. São Paulo: Bookman, 2009.

HOCK, R. E. E. Antecedentes atitudinais de comportamento de cidadania organizacional percebidos em mulheres da equipe de enfermagem de um hospital público de Santa Maria. 2010. 103 f. Dissertação (Mestrado em Administração) - Universidade Federal de Santa Maria, Santa Maria, 2010.

JARDIM, M. F. Valores organizacionais e civismo no sistema judiciário mineiro. 2009. 147 f. Dissertação (Mestrado em Administração) - Faculdade Novos Horizontes, Belo Horizonte, 2009.

KATZ, D.; KAHN, R. L. Psicologia social das organizações. São Paulo: Atlas, 1974. KOTLER, P.; KELLER, K. L. Administração de marketing: a bíblia do marketing. 14. ed. Pearson: São Paulo, 2012.

LOPES, L. F. D. et al. Caderno didático: estatística geral. Santa Maria: UFSM, 2008. MARINOVA, S. V.; MOON, H.; VAN DYNE, L. Are all good soldier behaviors the same? Supporting multidimensionality of organizational citizenship behaviors based on rewards and roles. Human Relations, v. 63, n. 10, p. 1463-1485, 2010.

MARTIN, S. B. Redes sociais e flexibilidade do trabalho: uma análise comparativa. Revista Latinoamericana de Estudios del Trabajo, v. 3, n. 6, p. 9-38, 1997. 
MILLER, T. Cultural citizenship. In: ISIN, F. E.; TURNER, B. (Eds.), Handbook of Citizenship Studies. London: Sage, 2002, p. 231 - 244.

MINAYO, M. C. S. O desafio do conhecimento: pesquisa qualitativa em saúde. 12. ed. São Paulo: Hucitec, 2010.

NASRA, M. A.; HEILBRUNN, S. Transformational leadership and organizational citizenship behavior in the arab educational system in Israel: the impact of trust and job satisfaction.

Educational Management Administration \& Leadership, v. 43, n. 1, p.1-17, 2015. PODSAKOFF, N. P. et al. Individual - and organizational-level consequences of organizational citizenship behaviors: a meta-analysis. Journal of Applied Psychology, v. 94, n. 1, p. 122-141, 2009.

PODSAKOFF, N. P. et al. Consequences of unit-level organizational citizenship behaviors: a review and recommendations for future research. Journal of Organizational Behavior, v. 35, n. S1, p. S87-S119, 2014.

PODSAKOFF, P. M.; MACKENZIE, S. B. Organizational citizenship behaviors and sales unit effectiveness. Journal of Marketing Research, v. 31, n. 3, p. 351-363, 1994.

PODSAKOFF, P. M. et al. Organizational citizenship behaviors: a critical review of the theoretical and empirical literature and suggestions for future research. Journal of Management, v. 26, n. 3, p. 513-563, 2000.

PORTO, J. B.; TAMAYO, A. Desenvolvimento e validação da escala de civismo nas organizações. Estudos de Psicologia, v. 8, n.3, p. 393-402, 2003.

PORTO, J. B.; TAMAYO, A. Valores organizacionais e civismo nas organizações. Revista de Administração Contemporânea, v. 9, n. 1, p. 35-52, 2005.

SAHIN, S. Examining organizational citizenship behaviours (OCBS) of teacher candidates at faculty of education. Croatian Journal of Education, v. 15, n. 3, p. 73-97, 2013. SAMPIERI, R. H.; COLLADO, C. F.; LUCIO, P. B. Metodologia de pesquisa. São Paulo: McGraw-Hill, 2006.

SANTOS, A. S. Comportamentos de cidadania organizacional: investigando novas e velhas relações. 2011. 128 f. Dissertação (Mestrado em Administração) - Instituto Universitário de Lisboa, Lisboa, 2011.

SANTOS, R. M. M. Análise de comportamentos de civismo organizacional em um hospital universitário. 2009. 43 f. Monografia (Especialização em Gestão Universitária) Universidade Federal de Brasília, Brasília, 2009.

SIQUEIRA, M. M. M. Antecedentes de comportamentos de cidadania organizacional: a REAd | Porto Alegre - Vol. 23 - No Especial - Dezembro 2017 - p. 262-291 
análise de um modelo pós-cognitivo. 1995. Tese (Doutorado em Psicologia) - Universidade de Brasília, Brasília, 1995.

TAMAYO, M. R.; TRÓCCOLI, B. T. Exaustão emocional: relações com a percepção de suporte organizacional e com as estratégias de coping no trabalho. Estudos de Psicologia, v. 7, n. 1, p. 37-46, 2002.

VAN DYNE, L.; ANG, S.; KOH, C. Development and validation of the CQS: the cultural intelligence scale. In: ANG, S.; VAN DYNE, L. (Eds.). Handbook on cultural intelligence: theory, measurement and applications. New York: M. E. Sharpe, 2008, p. 16-38.

VAN MANEN, M. Researching lived experience. New York: State of New York Press, 1990.

VINK, P.; STAHRE, J. The future of intelligent manufacturing systems and human factors. In: Proceedings of 16th World Congress on Ergonomics. International Ergonomics Association, Holanda, p. 1-5, 2006.

YAGHOUBI, N. M.; SALARZEHI, H.; MOLOUDI, J. The relationship between human resource productivity (HRP) and organizational citizenship behavior (OCB). African Journal of Business Management, v. 7, n. 32, p. 3168-3176, 2013.

YAGHOUBI, N. M.; YAZDANI, B. O.; KHORNEGAH, K. The relationship between organizational citizenship behavior (OCB) and social capital (SC). American Journal of Scientific Research, v. 24, p. 121-126, 2011.

YIN, R. K. Estudo de caso: planejamento e métodos. 4. ed. Porto Alegre: Bookman, 2010. 